\title{
Business Improvement Districts: A Systematic Review of an Urban Governance Model towards City Center Revitalization
}

\author{
Pedro Guimarães (1D) \\ Center for Geographical Studies, Institute of Geography and Spatial Planning, Universidade de Lisboa, \\ 1600-276 Lisboa, Portugal; pedroguimaraes@campus.ul.pt
}

check for updates

Citation: Guimarães, P. Business Improvement Districts: A Systematic Review of an Urban Governance Model towards City Center Revitalization. Land 2021, 10, 922. https://doi.org/10.3390/ land 10090922

Academic Editor: Fabrizio Battist

Received: 6 August 2021

Accepted: 30 August 2021

Published: 1 September 2021

Publisher's Note: MDPI stays neutral with regard to jurisdictional claims in published maps and institutional affiliations.

Copyright: (c) 2021 by the author Licensee MDPI, Basel, Switzerland. This article is an open access article distributed under the terms and conditions of the Creative Commons Attribution (CC BY) license (https:// creativecommons.org/licenses/by/ $4.0 /)$.

\begin{abstract}
For some time, business improvement districts (BIDs) have entered into the discourse and practice of academics and urban planners. This model for town centre revitalization was created in North America, whose success has led to its transfer to a growing number of countries. This evolution highlights the importance of BIDs as an urban planning practice, as well as an object of study for academics interested in new models for intervening in central urban areas. BIDs are public-private partnerships, framed within an entrepreneurial logic of urban management that aims to increase the cities' competitiveness. In this article, we aim to unfold the main research subjects of the literature focused on BIDs. We develop a systematic review for said endeavor, resorting to the established PRISMA protocol. After the screening and analysis of selected articles, four main research subjects were documented: (i) urban governance; (ii) urban policies: mobility and transfer; (iii) activities/axis of intervention; and (iv) types of BIDs/places of intervention. The selected literature enhances the contradictory nature of BIDs, ranging from the economic revitalization of city centres to the occasional exclusionary stance, in which it is developed. Our analysis also points to the important role of different actors in all stages of the policy transfer and implementation.
\end{abstract}

Keywords: business improvement districts; neoliberalism; neoliberalisation; policy transfer; policy mobilities; public-private partnership; urban governance; privatization; urban regeneration

\section{Introduction}

For some time, Business Improvement Districts (BIDs) have entered into the discourse and practice of academics and urban planners [1]. It is not a new model for town centre revitalization, as its origins can be traced back to the city of Toronto, Canada. In this city, in the late 1960s and early 1970s, two peripheral shopping centers and the expansion of the subway line affected the vitality of certain inner-city areas. In order to counteract this evolution, some businessmen from the axis of Jane St-Bloor St-Runnymede Rd proposed the creation of what became known as Bloor West Village Business Improvement Area [2].

In its essence, the BID model is simultaneously a new form of urban governance [3] and a retail-led urban regeneration initiative. Business owners of a delimited area are required to pay a tax; depending on the country, it may be mandatory for other agents to contribute to what is going to be further redistributed to the area (through a set of activities and services) to improve the economic viability of that same area [4]. BIDs are enacted after democratic elections, in which the majority of business owners vote positive on the execution of a BID for a usual period of five years. At the end of this period, a new election is held, usually with success, as argued by McCarthy and Doyle [5], regarding the United Kingdom (UK) context. In terms of governance, local entrepreneurs and key private and public stakeholders are involved in the pursuit of the common goal of town centre revitalization. In this framework, the term 'revitalization' is linked with an increase in the vitality and viability of a given area, particularly relevant in the UK urban policies from the 1990s onwards [4,5]. In this context, vitality refers to the footfall in a given area and viability refers to the economic performance and profitability of businesses. Moreover, 
the wide variety of agents that may be mobilised into the development of BID projects represents a bottom-up approach towards the improvement of certain urban districts. This modus operandi presents some novelty, when compared to the traditional top-down approaches in urban regeneration, where central and local governments usually adopt a more authoritative stance and impose their vision.

In regards to the latter case, BIDs fit within the urban regeneration processes [6]. Urban regeneration is understood as the interventions aimed to solve urban problems and urban decline [7-9], connecting with sustainability goals only when it represents an integrated vision that combines the economic, social, and environmental dimensions. Different sectors may be involved in urban regeneration, accompanying or leading the developed projects. For instance, Alves [10] and Balsas [11] discussed how the appointment of the city of Porto as the 2001 European Capital of Culture had an important role in the urban transformation of that city, in what may be designated as culture-led urban regeneration. In the same rationale, the Guggenheim Museum has become a benchmarking for this type of intervention, functioning as a role model for museums as catalysts for urban regeneration $[12,13]$.

The incorporation of retail (having more than an accessory role) in urban regeneration must be seen as a part of an evolutionary path, in which this sector slowly gained importance in public policies, as further explained. Stretching from the idea that it was a parasitic activity that did not actively contribute to the urban economy and, rather, acted as mere intermediaries between producers and consumers [14], retail has acquired a position of relevance, especially after the recognition of its key role in the vitality and viability of town centres $[15,16]$. In academia, part of this discussion arose with the appearance of peripheral commercial precincts (such as the hypermarkets in France that led to the enactment of the Loi Royer [17] or the shopping centres in the UK and the subsequent implementation of the town centre first policy [18-20]). Progressively, the incorporation of retail in urban policies occurs, and retail planning began to acquire particular relevance from 1980s onwards $[21,22]$. The incorporation of retail as an anchor of urban regeneration processes arose in this period in two different ways, both associated with the improvement of central urban districts. The first relates with the implementation or rehabilitation of shopping centres in town centres, of which West Quay in Southampton is an example, as analyzed by Lowe $[23,24]$. The second concerns place management initiatives, especially through town centre management schemes (TCM), widely disseminated throughout the UK [25]. This type of intervention is based on the collaboration between private and public agents and on the voluntary financial contributions for the development of promotional activities, as well as other actions towards the improvement of intervened areas [26]. TCM-based initiatives proved to be successful, attested by the large dissemination within the UK [27] and the transfer of the model to countries such as Italy [28], Spain [29], and Portugal [26]. Despite the necessity and benefits of an integrated management of town centres was confirmed through these schemes, especially if one considers the growing importance of cities' competitiveness and the role of urban marketing on such a process [30], the voluntary financial contribution undermined their effectiveness and temporal sustainability [25], mostly due to the existence of free-riders, i.e., businesses that benefited from the activities but did not contribute to them [31]. This is the fundamental difference between TCM and BIDs, as these latter initiatives imply the existence of a mandatory fee for entrepreneurs and/or property owners of a delimited area, which allows them to carry out a variable set of activities, with the aim of revitalizing it [32]. Although one may recognize the evolutionary path of the BID model that is currently leading some of the existing projects to encompass more than retail, BIDs are originally embedded on the logic of economic revitalization of urban districts [33] that possess a meaningful set of retail and services. Within the wide set of urban regeneration approaches, especially the ones that consider retail as the main anchor of the process, BIDs currently stand out in a twofold. Firstly, the core activities developed by BIDs are easily adjustable and quick to implement, when compared to the key elements of other main retail-led urban regeneration projects, such as the aforemen- 
tioned implementation or rehabilitation of shopping centres in town centres $[23,24]$. Most of the traditional retail-led urban regeneration projects suffer from what one may call the crystallization of actions and impacts. That is, they are interventions that are too focused on a narrow timeframe and do not consider the dynamic nature of urban areas; thus, they are at the risk of quickly becoming misfit. On this matter, Guimarães [14] analyzed how a retail-led urban regeneration program, developed in Portugal (based on the financial support for retail outlets modernization and the physical rehabilitation of intervened areas) in the 1990s and 2000s, failed to achieve its goals of revitalizing central urban areas because at the end of the intervention, initially outlined actions were no longer adjusted to the reality of disturbed areas (among other reasons). Secondly, the relevance of BIDs also arose from the awareness that urban decline can hardly be fought through sectoral interventions. As Tallon [9] puts it, "City centre management involves a team approach to a comprehensive range and combination of activities and improvements, and demands close planning, working and financial co-operation." (p. 189). Thus, through the recognition that integrated interventions are needed to solve the decline of some urban areas, BIDs, as a pivotal structure between different public and private actors, reveal their importance in the current context of urban planning. Moreover, BIDs, as a retail-led urban regeneration tool, must also be framed in the wider retail planning policies, especially within the Western European context. These types of urban policies are composed by legislation and other measures to control the evolution of retail [21]. It is usually characterized by alternating between periods of less restrictiveness (to enhance innovation in the commercial sector) and periods of greater control (usually with the aim of protecting the consolidated traditional centres of commerce) [14]. Resorting to the aforementioned Western European context, the liberalization of retail planning policies in the 1980s and 1990s enhanced the dissemination of peripheral shopping centres in several countries [19,26]. In the late 1990s, a shift occurred with the enactment of restrictive retail planning policies, towards the increase of the vitality and viability of consolidated town centres. In this period, part of the policies that were enacted focused largely on restricting the peripheral location of new commercial spaces. In this sense, it was assumed that these restrictions would indirectly favor the more central areas [18]. For example, in the United Kingdom (often used as a reference on the subject), this rationale was centered on the Town Centre First policy and operationalized with mechanisms such as the 'need test' [19]. However, in addition to the aforementioned indirect actions on city centers, it was deemed necessary to act proactively in these areas. The relevance of TCM [27] and the subsequent BIDs follow this understanding and are simultaneously in line (and we must add that in a somewhat antagonistic way) with a more dominant, liberal thought that requires a deeper involvement of the private sector in urban management [4].

Despite the fact that it has celebrated half a century of existence, initially, the BID model was, essentially, most known for its implementation and dissemination in Canada and in the US [34]. It is through its transfer into different countries, such as Germany [35,36], South Africa [37], and the UK [38,39], that the model widespread. In the European context, the UK experience with BIDs is setting the pace for its dissemination across the continent. This guidance position is not necessarily imposed; it is mainly due to the success and widespread effect of BID projects in the UK. According to Grail et al. [38], at the end of 2018, 303 BIDs were operating throughout the UK.

A proper interpretation of BIDs must also take in consideration its essence and adaptability. In its essence, BIDs are a legal mechanism (among several others) through which a tax is collected from businesses and/or property owners to improve the economic environment of a certain area $[1,3,32]$. This distinguishes this model from others, such as the aforementioned TCM (known for its dissemination in the UK) [25]. On this issue, Mullin and Kutval [40] claim attention for programs such as the Main Street Program of the National Trust for Historic Preservation, the Downtown Development Authority Program, and the Tax Increment Financial Acts that co-exists with BIDs as urban policies in the US. This also means that, as referenced by Ward [41], BIDs may often exist (even if under other 
designations) as an adjustment to the country where the model is being developed or to better fit specific aspects of given BIDs, namely the objectives and targeted sectors. The second issue concerns how (departing from the standpoint of a mandatory fee for urban revitalization) BIDs are adapted to fit into other countries' national legislation and urban planning practices. In this regard, it is no coincidence that the model better fits in countries with a strong neoliberal approach to urban economy [41]. Although it is no surprise that this stance is easily recognizable in the US and in the UK, where the private sector is called to participate in the actions of urban revitalization that concerns them, this neoliberal approach is gaining relevance in a wider number of places. Countries with a strong influence on the public sector (e.g., Portugal and Spain) are also discussing the possible adoption of this new model of governing town centres $[1,26,42]$. On another scale, the importance of BIDs must also be interpreted as a model that allows the development of local, tailor-made activities. In this sense, it considers the characteristics, needs, and shortcomings of each intervened area and develops an intervention plan to address these local urban problems. A significant part of existing research on BIDs is, thus, context sensitive, in the sense that it focusses on the challenges of BID transfer and implementation in different countries, providing evidence-based learning from specific geographical contexts. Nevertheless, there is a gap in comprehensive research on the thematic; by being case-study-centered, most research simply looks into the specific issues of each analyzed area, whether it be the transfer of BIDs into the respective national legislation or the activities developed to address local problems. However, we must stress that by specifying this gap, we do not intend to assume that comprehensive studies do not exist. Studies such as the ones developed by Hoyt and Gopal-Agge [43] and Morçöl et al. [44], as well as the more recent studies from Prifti and Jaupi [45] and Grail et al. [38] have been important academic resources. We consider, however, that these types of studies are not as numerous as would be desirable, given the relevance of BIDs for academics and practitioners. In this sense, recognizing that there is a need for more wide-ranging research on BIDs, the aim of our article is (not neglecting local specificities) to provide a comprehensive overview to address the research question: "What are the main research subjects that stand out from the existing literature on Business Improvement Districts?". Our methodology is based on a systematic review, mobilizing the PRISMA protocol for said endeavor. The results of this review will sustain the grouping of the main research subjects concerning BIDs, after which an analysis of each subject will be carried out. Lastly, in the final section some discussion and conclusions will be established.

\section{Materials and Methods}

We have chosen to develop a systematic review to deliver a comprehensive understanding of the issues that guide research on BIDs. For that purpose, we have chosen the PRISMA statement. In the last decade, systematic reviews have been increasing in number and PRISMA has been widely acknowledged as a valid protocol for this methodological approach [46]. Not discarding its application in other research fields, this protocol has received particular attention from health sciences researchers [47-49]. The acceptance of this protocol within the scientific community can be explained by its meticulous process, with a checklist that guarantees, at least, the methodological validity of the given research. Moreover, the rigorous detailed information also allows the research to be replicable [46].

We have selected the Elsevier's Scopus database as our source of information. We should clarify that other databases could have been chosen, especially the Web of Science. Our option was justified for two reasons: (i) there was an acknowledged substantial overlap between the two mentioned databases; (ii) despite this overlap, in the field of social sciences, especially in human geography (and its sub-fields), Scopus was more comprehensive. Therefore, because we have aimed to have a broader set of publications, this latter database was selected. In this database we searched for publications that contained the term "Business Improvement Districts" within the title, abstract, or keywords. This action was performed on 5 May 2021. At this point, we did not refine the search, and a total of 
200 results were extracted. All of the work was developed in person by the author, without any support from an automation tool. The analysis of the results, per year of publication, confirmed the growing interest of the subject, especially after the mid-2000s, when the model was being transferred to different countries (Figure 1).

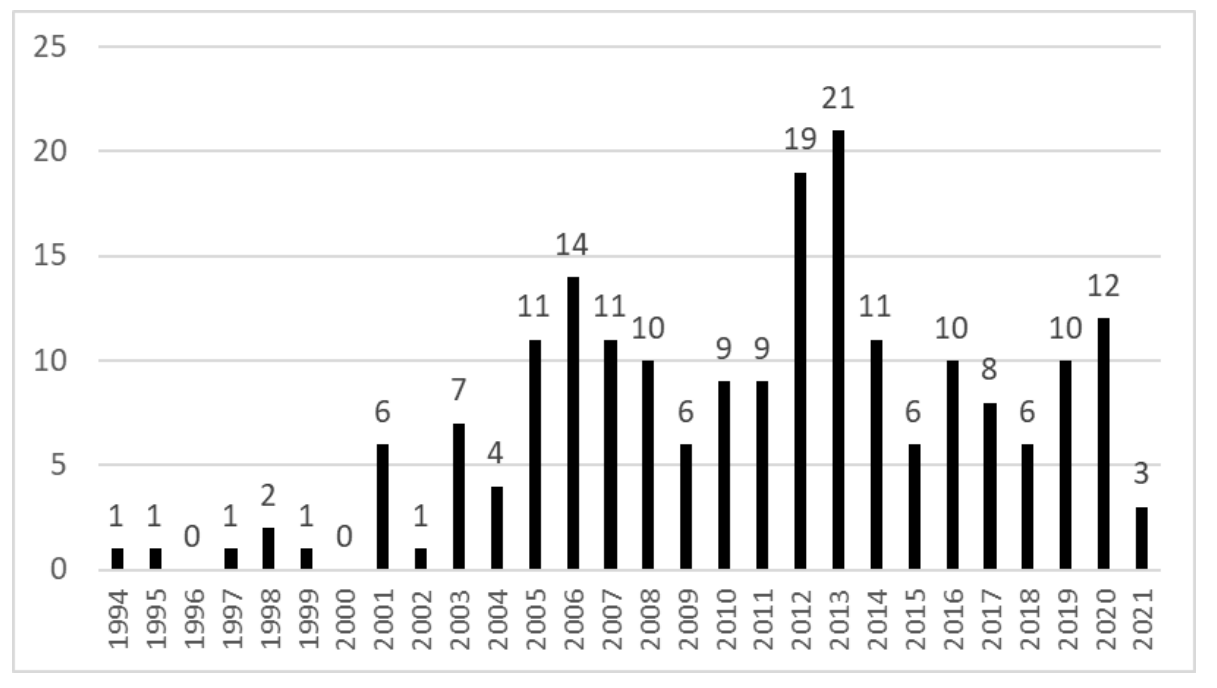

Figure 1. Number of publications on the subject of business improvement districts, per year. Source: author (2021).

The screened publications appeared in a wide array of journals, ranging from research fields such as public administration, geography and planning, law, and economics. This variety reflects the comprehensiveness of BIDs, whose essence, organizational structure, and activities developed can be understood and interpreted from different perspectives and dimensions, as will be detailed below. An initial screening of the articles also reveals the importance of some journals to the scientific debate on the subject. To this matter, the 2012 special issue published in the European Urban and Regional Studies (6 articles), the 2006 special issue of the International Journal of Public Administration (10 articles), and the Journal of Urban Regeneration and Renewal (with 8 publications since 2013) have been important spaces for debate and dissemination of knowledge regarding BIDs.

An initial identification of the results led to the exclusion of 28 publications for the following reasons: duplicated $(n=1)$; written in German $(n=9)$; books or book chapters not available $(n=9)$; article abstracts not available $(n=8)$; and newspaper article $(n=1)$. A further screening was developed, based upon the titles and abstracts of the remaining 172 publications. During this step, 31 results were found to be unrelated to the subject of our research. As such, 141 publications were considered eligible to be included in our analysis (Figure 2).

As mentioned above, our main goal is to list and discuss the main research subjects identified in the literature that focused on BIDs. Apart from the above identification of publications, based on the screening of the titles and abstracts, we resorted to a further refinement, using the keywords to determine the main research subjects analyzed in BID literature, for further study and discussion. The total number of keywords, of all 200 identified publications, was 626 . However, we had already excluded 51 publications, for various reasons (see aforementioned explanation); we created a sheet with only the keywords from the 141 selected publications, which led to the retrieval of 71 keywords (leaving a total $n=555)$. The keywords "Business Improvement Districts" $(n=77)$ and "BIDs" ( $\mathrm{n}=7)$ were also excluded; they are redundant, considering the first keyword was already the main initial search term within the Scopus database, and the second keyword was the abbreviation of the former. 


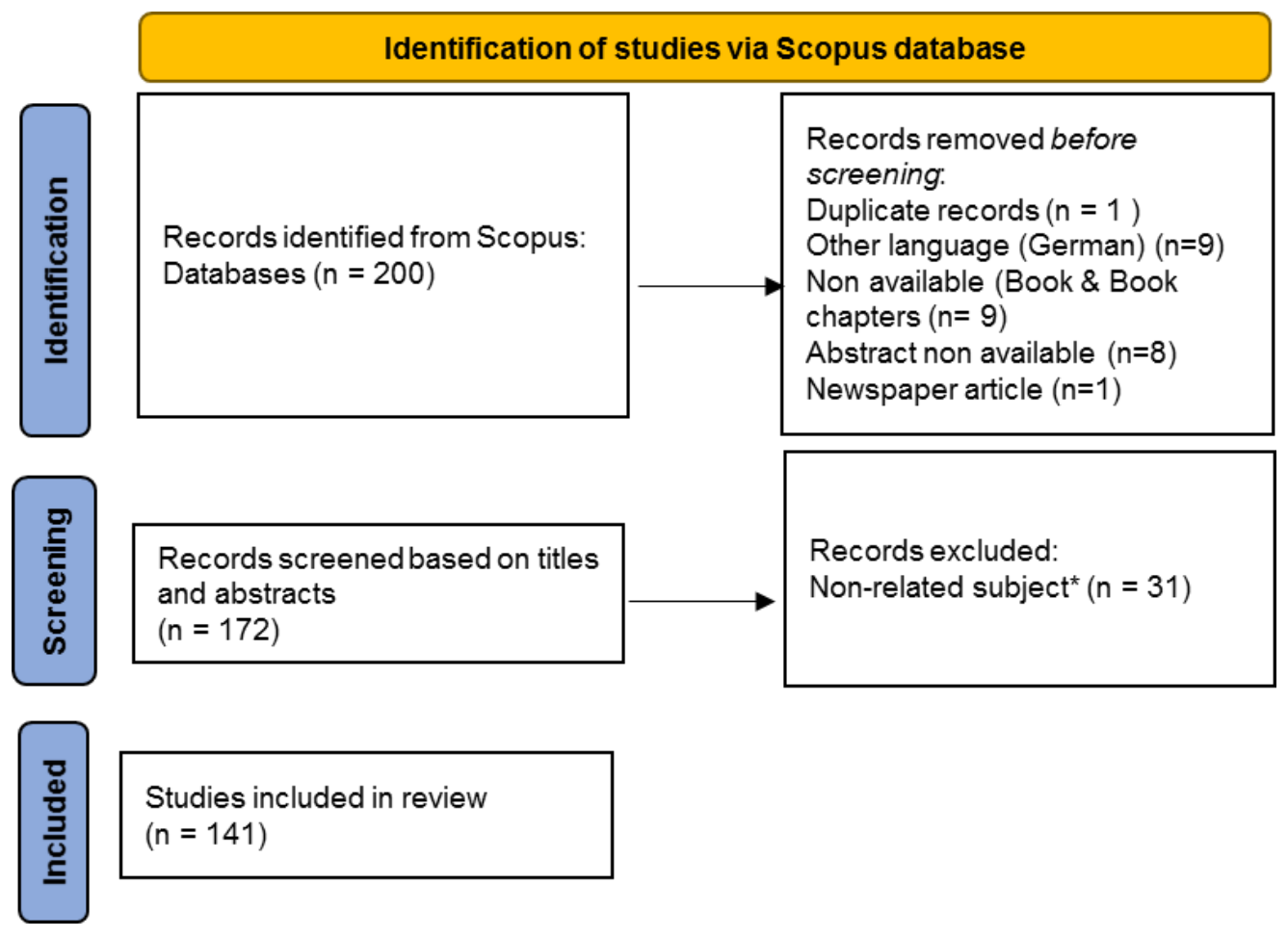

Figure 2. Procedure for the selection of publications. Source: adapted from Page et al. [50].

In the second step, the quantification of each keyword, according to the number of articles using it, was performed. Sorting by the number of times it was used enabled the verification of its relevance, in the scope of the literature on BIDs. In the third step, a new screening of the ordered keywords was carried out to search for similarities between them and to group them, with a twofold objective. The first objective was to consider the relevance of each keyword, within the overall scope of this article goal. Consequently, it was considered that 172 keywords were not related to the study and were excluded. The large majority of them only appeared once within all analyzed publications and, in any case, this meant that a single publication had all keywords excluded (which would make us ponder the relevance of such a publication). This process resulted in 299 keywords that were considered valid for the prosecution of the research. The second objective was to group the keywords according to their thematic similarity (and, consequently, the publications from which they were extracted) within main research subjects analyzed in the literature on BIDs. This was performed through a qualitative approach on the author's understanding of the level of thematic similarity among all selected keywords. We must also clarify that the grouping of the keywords was made based on how each one was interpreted, in light of the literature on BIDs. In this regard (and using the word "governance" as an example) our aim was not to analyze the conceptual framework of this concept per se. On the contrary, we sought, in a concrete way, to understand how this concept was mobilized and framed by the various authors who analyzed BIDs. In this sense, the following analysis was guided by the theme of BIDs (not meaning that each one of the keywords cannot be used in studies on other themes in a different way and following another perspective). This process allowed the grouping of keywords in four major research subjects (Figure 3) that reflected the concerns and main research subject of academics: (i) urban governance (keywords $n=127$ ); (ii) policy mobility and transfer (keywords $\mathrm{n}=76$ ); (iii) place of execution/type of BIDs (keywords $\mathrm{n}=33$ ); and (iv) activities (keywords $\mathrm{n}=63$ ). In the next section, a definition of BIDs will be discussed. Following, the neoliberal stance that is transversal to almost all, if not all, selected publications will be analyzed. After these two sub-sections, each of these research subjects will be analyzed individually. For the analysis of all sub-sections of the section 'Results', we will only resort to the bibliography list that was previously extracted, 
as detailed previously. This selection of research subjects has a qualitative and subjective character. Thus, other choices could have been made, mainly through the division into more research subjects. However, in our opinion, the current four groups fit into the overall topics discussed in BID literature, allow for its analysis, and are broad enough to fulfil the goals established for this article. Furthermore, with more group desegregation, there was a risk for the analysis to be too specific, a gap we had previously identified in the literature and that we tried to overcome. We must also add that our aim was not to analyze whether each publication focused on more than one research subject (which we realized is likely to occur to some extent, especially in the respective theoretical section). In our research, we used the research subjects as our object of study, which means that a specific reference may have been used in the discussion of more than one research subject.

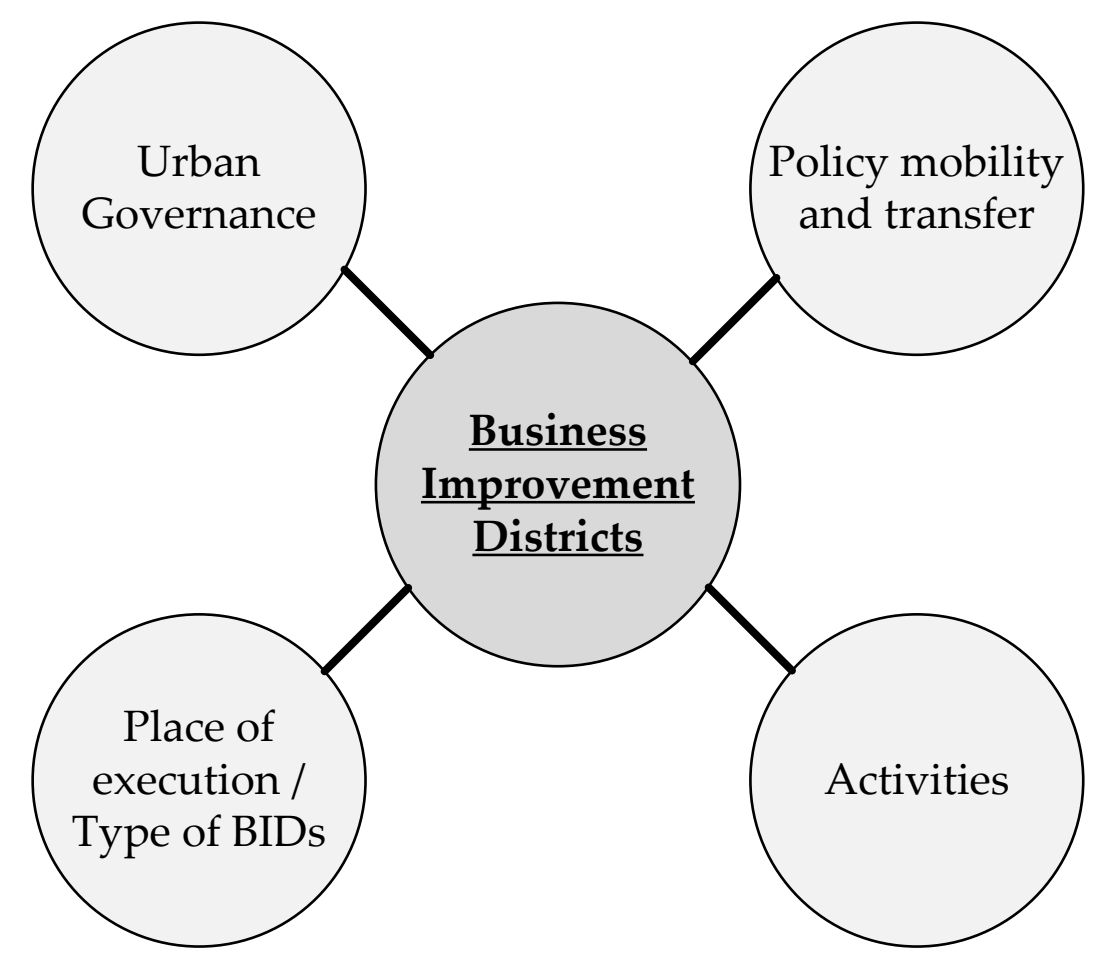

Figure 3. Main research subjects addressed in BID literature.

\section{Results}

\subsection{Conceptualizing a Definition of Business Improvement Districts}

BIDs are seen as a benchmarking for the revitalization of city centres in a growing number of countries. Despite their acknowledged relevance, there is no widely established definition $[38,51]$. This is likely due to the heterogeneity that characterize BIDs, attested by the large number of countries that have adopted the model, the diverse range of activities that may be developed, and even the dissimilar places where BIDs may be implemented (i.e., town centres vs peripheral areas; commercial districts vs industrial areas; and large cities vs small or rural areas). Moreover, understanding BIDs as a model for town centre revitalization also means that one must be aware (as Ward [41] noted) that often, within the policy transfer to other countries, BIDs may assume other designations, such as 'special improvement districts', 'public improvement districts', or 'downtown improvement districts' [41] (p. 6580); this introduces a new layer of complexity in providing a definition of BIDs that can be broad enough to capture its heterogeneity. Most definitions, thus, tend to be inclusive, such as Ziebarth's [52] (p. 128) definition: "BIDs are private non-profit organizations established primarily in urban areas to deliver public services and improve economic conditions by imposing additional assessments on property owners" or Han et al.'s [51] (p. 659): "BIDs are self-assessment districts that are enabled by state laws, 
authorized by local governments, and approved by property owners, with the purpose of delivering supplemental public services to the districts". Recognizing the difficulty of elaborating an inclusive definition, several authors tend to focus on the common elements that characterize the different projects. To this matter, drawing a synthesis, Brettmo and Browne [53], Grail et al. [38], and Ratcliffe and Flanagan [39] highlighted the features (placed in Table 1) with a meaningful overlap among them.

Table 1. Consensual characteristics regarding the establishment and execution of a BID.

\begin{tabular}{|c|c|}
\hline \multirow{5}{*}{$\begin{array}{l}\text { Brettmo and } \\
\text { Browne (2020) }\end{array}$} & Public-private partnership \\
\hline & Non-profit organization. \\
\hline & Operates on a designated geographical area in an urban area. \\
\hline & Driven by property owners and/or business owners (occupiers, tenants). \\
\hline & $\begin{array}{l}\text { The main aim is to improve attractiveness and promote the commercial area } \\
\text { for visitors, workers, customers and increase the value of properties. }\end{array}$ \\
\hline \multirow{3}{*}{ Grail et al. (2019) } & $\begin{array}{l}\text { Mechanism whereby relevant property/business owners elect to make a } \\
\text { collective contribution to secure private capital to fund activities within a } \\
\text { designated commercial area to improve its attractiveness. }\end{array}$ \\
\hline & Existence of a clearly delineated spatial remit. \\
\hline & Partnership modus operandi between public and private sector actors. \\
\hline \multirow{5}{*}{$\begin{array}{l}\text { Ratcliffe and } \\
\text { Flanagan (2004) }\end{array}$} & $\begin{array}{l}\text { Co-operation between property or businesses owners, based on cost-sharing } \\
\text { of solutions for common problems in a specific area. }\end{array}$ \\
\hline & $\begin{array}{c}\text { Sustainable funding (temporarily), allowing for multi-year plans } \\
\text { and budgets. }\end{array}$ \\
\hline & Authorized by government through legislation. \\
\hline & $\begin{array}{l}\text { Permitted to provide business and property-related services within its } \\
\text { geographic boundaries. }\end{array}$ \\
\hline & $\begin{array}{c}\text { May be managed by an organization that is either a quasi-public agency or a } \\
\text { non-profit corporation. }\end{array}$ \\
\hline
\end{tabular}

\subsection{The Neoliberal Perspective within BID Literature}

The selected literature consensually recognizes a neoliberal stance in BIDs, as a part of a neoliberal urbanization [54]. In this sense, BIDs and other similar instruments consubstantiate "the adoption of neoliberal principles and practices at the urban scale" [37] (p. 122). Despite BIDs operate within the intermingled public-private sphere, they are privately run, which "allows private actors to manage directly several aspects of the daily life" [55] (p. 783). It is due to this private management of public areas that Kizildere and Chiodelli [55] further added that "Such privatization of the governance of urban space is seen as a constitutive element of the ongoing urban neoliberalization shaping many cities around the world". This is corroborated by authors such as Ward [41], according to whom BIDs are often associated with wider national neoliberal reforms and constitute an example of neoliberal urbanization. Under this consideration, the discourse of the inefficiency of public authorities in dealing with some urban decline is bridged through the "adoption of neoliberal principles and practices at the urban scale" [37] (p. 122), with BIDs being an example of such practices. On this matter, De Magalhães [4] discussed the incorporation of BIDs in the UK and added that BIDs mirror "the shift from managerial to entrepreneurial forms of urban governance, associated with the promotion of neoliberal solutions to societal problems by successive New Labour governments" (p. 145). This is in line with Richner and Olesen [56], who conceptualized BIDs as a neoliberal urban planning practice. According to these latter authors (p. 160), the adoption of BIDs in Denmark, as neoliberal instruments for urban regeneration in central areas, must also be framed "as part of a wider neoliberalisation of urban governance and policy-making". 
This internationalization of a neoliberal instrument, such as BIDs, is intensified by the current process of globalization. In this sense, the understanding of BIDs (as a neoliberal approach) is more than the delegation of powers to private agents, in what concerns the management of cities' central areas. It is also related to the conditions of the places from which BIDs are transferred. On this matter, Shaw [57] highlights the role of the city of New York in the international recognition of BIDs. The successful development of BIDs in this city and the overall appeal of New York City, as a must go destination, stressed the image of BIDs as an urban regeneration model. Thus, following the question asked by Shaw [57] "What city would not want to be like the Big Apple?", this city became a case study for the international benchmarking of the BID model. However, it must be noted that the adoption of some BIDs as relevant for benchmarking does not mean the modus operandi of BIDs towards urban revitalization is the same in every country that has adopted this model [58]. Local specificities are taken in consideration upon the transfer and incorporation of the BID model to national and local contexts (e.g., see the transfer of BIDs into South Africa, as analyzed by Didier et al. [37]). Moreover, what is also frequently criticized in the adoption of BIDs for the private governance of delimited areas is the easiness with which private management structures, such as the BIDs, have to make decisions that could be poorly faced if taken by public authorities. Valli and Hammami [59], focusing on Sweden, exemplified how there is a risk that BIDs (aiming to increase the attractiveness of the intervention areas, in a clear privilege of the economic dimension) may cause the economic and social exclusion of the most disadvantaged citizens. In this sense, concerns about the fact that the BIDs reflect a neoliberal approach takes into account aspects such as the accountability of their actions and the direct and indirect spillover effects on the social sustainability of intervened areas.

\subsection{BIDs as an Instrument towards Cities' Governance}

This is the dimension most referred to by selected publications. Within all the retrieved keywords, the four most common fits this dimension: "Public-private partnership", "Privatization", “Town center management", and "Urban governance" (Figures 4 and 5). Part of the remaining keywords are extremely related to these four keywords. For instance, "Local Governance", "Metropolitan Governance", "Governance", and "Urban governance networks" are to be understood as synonyms of "Urban Governance"; thus, if grouped, it would acquire an even more prominent position. However, it was chosen to present these words disaggregated, more accurately reproducing the way they are found in the respective publications.

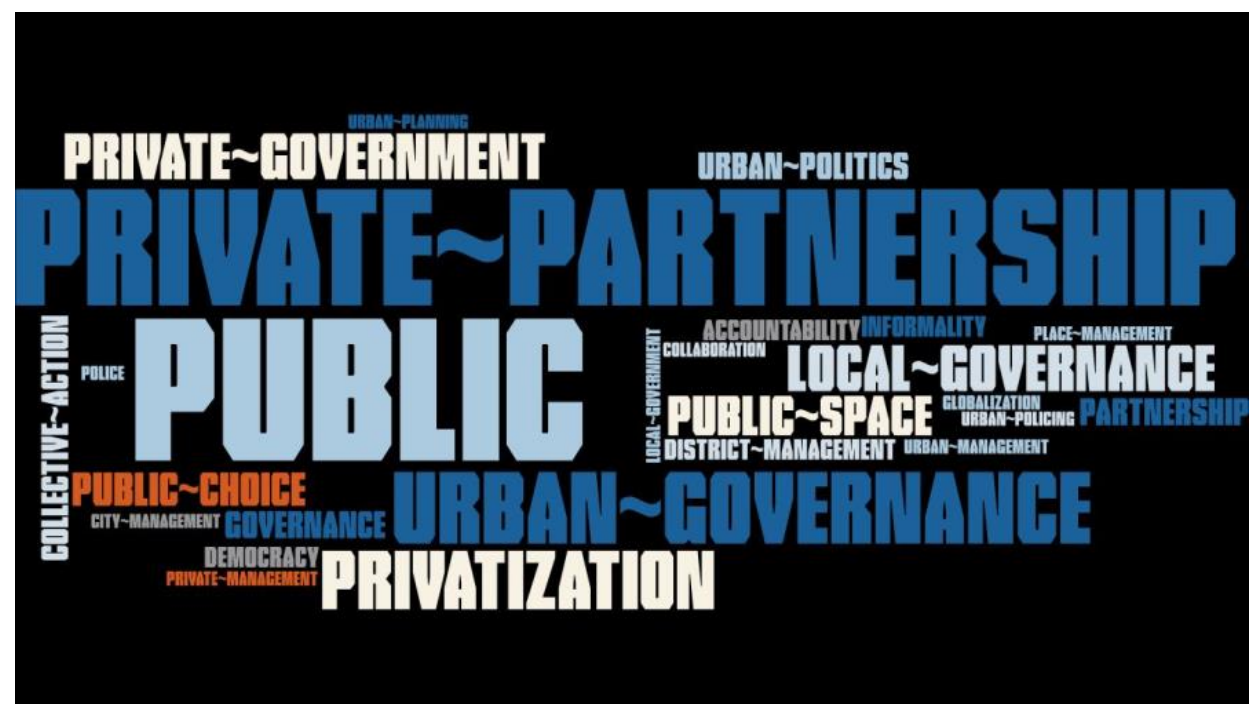

Figure 4. Word cloud extracted from keywords that fit the dimension "Urban Governance". 




Figure 5. List of keywords from the research subject "Urban Governance". Source: author (2021), after initial screening and selection of publications. Note: in this figure, only keywords with two or more listings were included.

The discussion developed in the articles using these keywords followed (most of the time) a dual perspective. In the first perspective, partnerships amid a multitude of agents from the public and private spheres were seen, indisputably, as the basis of BIDs and as a method that would "enable the sharing of resources, ideas, and funds to meet various goals" [60] (p. 203). Under this consideration, there is an assumption that joint work produces better and wider outcomes of what would be achieved if the different agents pursued their objectives individually. Moreover, for authors such as Browne et al. [61], the active involvement of local authorities in BID activities can be essential for mediating and unlocking some solutions regarding the execution of each project's business plan. The second perspective is embodied by the negative considerations regarding the results of those partnerships. One of the issues lies on the contradiction regarding public-private, which some authors argue to be not a straightforward approach. For instance, Ha and Grunwell [62] (p. 95) stress the private role of BIDs, as they are "managed by a private, non-profit organization that is subject to a board made up of stakeholders, primarily business people and landowners, with some seats reserved for public officials, residents, community board members, and non-profit representatives". Nevertheless, as pointed by Gross [63], BIDs operate in public spaces and are legitimized by the public sector, not only at the national level (through the creation of specific legislation) but also at the local level (through the direct involvement in the execution of the different projects). Morçöl and Karagoz [64] further added to this discussion, stressing that BIDs are more than publicprivate partnerships. These authors consider BIDs to be actors in an urban governance network. Although there are a meaningful number of articles that specified that BIDs constituted as forms of urban governance or as actors in such networks [3,58], the selected literature is not straightforward regarding the composition and implications of this urban governance structure or network, per se. To this matter, Briffault [65] seminal work is essential, as the author debates the comprehensiveness of BIDs. In this work (one of the oldest within the selected literature) Briffault [65] argues that BIDs intermingle with public and private activities and services. BIDs constitute, in an early stage, an addition to the established urban governance, embodying an urban development program; in a second stage, once established and disseminated in a certain urban area, BIDs "become part of 
the long-term structure of urban governance" [65] (p. 469). This was corroborated by Justice and Goldsmith [66] (p. 108), according to whom, BIDs in the U.S. are familiar mechanisms and "even taken for granted by commercial revitalization professionals and business people". It is due to this integration of BIDs in the involvement of decision-making regarding urban districts of public access that some authors claim we are dealing with an entrepreneurial urbanism mechanism [64], with public spaces within cities to be privately managed $[63,67,68]$. This approach to the management of urban public spaces generated some consensual critics, mainly appointing BID models as a reflex of a neoliberal stance.

With the exception of the keyword "public-private partnership", which essentially concerns a method of intervention, "Privatization" is the second most used keyword and carries a negative standpoint from the part of the authors using it. According to Richner and Olesen [56], BIDs are an example of a contradictory neoliberal approach, operating to improve the respective town centre's economic environment and aiming to attract a wide number of consumers, while simultaneously contributing to the privatization of that same area, with possible indirect spillover effects, such as gentrification [59], which may put into question the public access to the area. Kizildere and Chiodelli [55] also added to the subject by stressing that BIDs represent a growing trend for private government, through which, the private sector is called on to develop actions that, despite the lack of general accountability for their results, still represent actions of political power [69]. Brooks and Strange [70] corroborated this idea. Drawing from these authors, BIDs represent private businesses and gather key stakeholders in their organization, including local authorities. However, the presence of BIDs (a privately managed urban governance structure aimed to solve urban problems that the traditional public sector representatives were unable to address) represents an example of a private government. Beside the concerns regarding the possible production or exacerbation of inequalities [4], concerns are also raised regarding the accountability of BIDs. As Becker [71] (p. 187) put it: "Business improvement districts (BIDs) fuse a public taxing entity and a private nonprofit into something neither completely public nor completely private". Gross [63] (p. 347) stressed that BIDs "empower private sector actors by allowing them to determine which services BID revenues will be applied to, how those services will be delivered and by whom". This author critic arose from the public nature of the space where BIDs are executed. Thus, as De Magalhães [4] argued, considering the diversity of the people that do not have a say on BID decisions (nonparticipant businesses, residents (in this case, not always), and other individuals), this means a significant variety of the population will be dependent on the work developed by private entities, without having formal and democratic representation.

\subsection{Urban Policies: Mobility and Transfer}

Policy transfer and mobility is a key issue in understanding how a given policy is created in a certain context, as well as how it is transferred and implemented in other environments and the impacts it produces. Policy transfer is common in policies of different natures, as well as in diverse administrative procedures. In what concerns our object of research (BIDs), policy transfer is the means through which BIDs are seen as a good practice by individuals and institutions in other countries (to be implemented in their own country to solve their specific problems). Upon its design and implementation in Canada, in the early 1970s [71], BIDs have seen a meaningful dissemination across several countries. This research subject is, thus, central for understanding and interpreting BIDs; in a narrower conception of the theme, even US BIDs should be read as introduced from other country. Most articles, focused on this research thematic, debated the policy transfer of BIDs into specific contexts; this is why several keywords mentioned specific places, whether it may be cities and/or countries (Figures 6 and 7). 


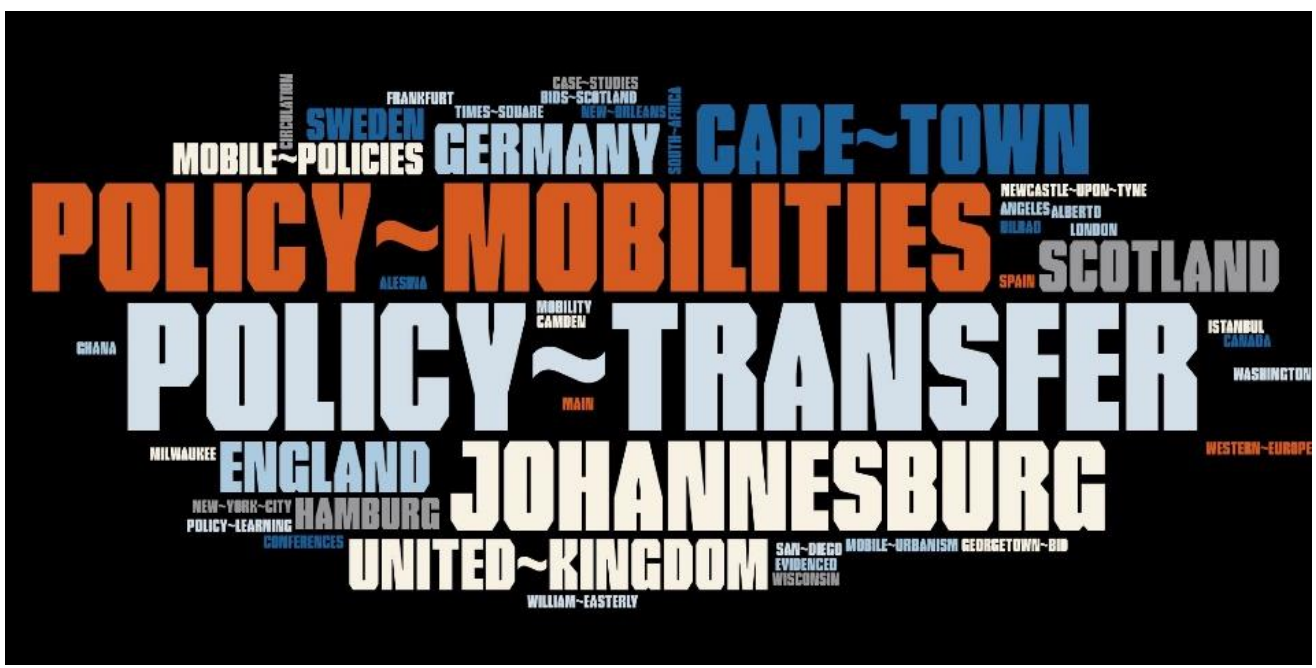

Figure 6. Word cloud, extracted from keywords that fit in dimension "Urban policies: mobility and transfer".

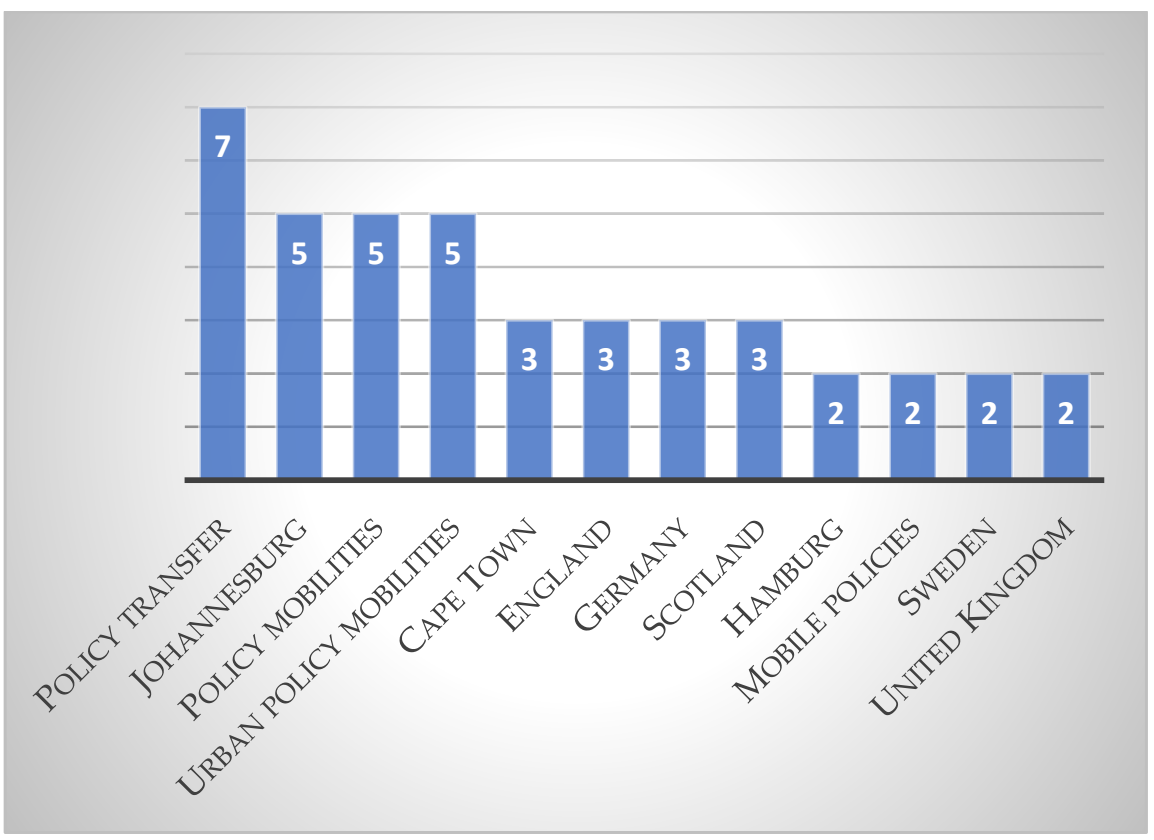

Figure 7. List of keywords from the research subject "Urban policies: mobility and transfer". Source: author (2021), after initial screening and selection of publications. Note: in this figure, only keywords with two or more listings were included.

In these publications, the conceptual framework of policy transfer and police mobilities were mainly mobilized to the understanding of BIDs as a "travelling concept", as Peyroux et al. [72] referred. Several authors agreed in what currently forms the basis of 'police mobilities'. On this matter, Michel [36] and Stein et al. [73] stressed the role of the ongoing process of globalization on the increase of the speed through which policies are disseminated. Tait and Hensen [74] corroborated this idea but also called for some caution when interpreting globalization, in the sense that it does not inevitably provokes the homogenization of places, mostly because the places where those models, ideas, or concepts would be implemented would provide a differentiating element. It is due to this heterogeneity that reveals itself in the legislation created for each country, in the privilege for certain activities in some countries and areas, and in the key agents involved, that BIDs must be seen as a glocal policy. Consequently, on the one hand, one can conclude that 
globalization is not the unique reason for the international mobility of BID models but significantly contributes to the current pace, as a part of the growing neoliberalisation of urban policies [56]. Nonetheless, on the other hand, it remains the essential question of who and how BIDs are incorporated (as an urban planning tool of the countries that adopted this model). A meaningful part of the literature on BIDs (at different scales) addresses, discusses, or, at least, mentions it. What is debated is the 'transfer agent' [75], i.e., the individuals responsible for putting BIDs rationale in motion and its incorporation in a given country, region, or city. Discussing how BIDs were transferred from the US to the UK, McCann and Ward [76] highlighted how the presence of some well-known individuals from the US BID scene in UK conferences, seminars, and workshops was important to trigger the translation of BID legislation into this latter country. This mobility of BIDs should not only be seen from the perspective of the transfer to 'some place' but also as the importing of an outside police, which means national and local representatives must be willing to incorporate it. On this matter, Stein et al. [73] (p. 36) stated that city managers are increasingly forced to scan the globe for new and better strategies to cope with their local problems. Tait and Jensen [74] were in line with this thought, considering urban planners and individuals from city governments as essential in the translation of urban policies.

Besides the importance of these individuals as transfer agents, some articles also highlighted the role of specific events as key in policy transfer. In their analysis of transferring BIDs into the Swedish planning framework, Cook and Ward [75] stressed the role of conferences and workshops, with whom city officials, academics, practitioners, consultants, and other agents gathered to share knowledge and discuss the possibility of adapting BIDs for the Swedish context. Similarly, Michel and Stein [58] (p. 80) also stated how, in Germany, a conference on urban entertainment centers and private planning triggered a discussion of BIDs that led to a study on the possible transfer of the model to the country.

The systematic review that we have proposed developing also allowed the apprehension of the role of academic journals in the process. On this matter, it must be added that (as referred to in the methodological section) some journals have also been performing the function of transfer agents. The 2012 special number of the European Urban and Regional Studies (EURS) contains 5 articles on policy transfer and the execution of BIDs in Canada [77], Germany [35], Johannesburg [78], Los Angeles [68], and Sweden [75], as well as a conceptual editorial [72] and three more articles on the subject, between 2017 and $2021[56,59,73]$. It is interesting to note that the (temporal) preceding special issue of the International Journal of Public Administration, from 2006, still possesses an important role within the BID policy transfer process; in this case, the published research retains an advocacy power, as most of the articles analyzed BIDs in specific North American contexts, namely: Southern California [79], Washington [80], Pennsylvania [81], Philadelphia [82], New Jersey [66], and Atlanta [83]. In this analysis of the role of journals from the selected publications, the Journal of Urban Regeneration and Renewal has also been a relevant communication mechanism for the discussion on BIDs, combining published articles from academics, as well as practitioners, attesting the close link and importance of different agents on the matter of BID policy transfer.

\subsection{Activities/Axis of Intervention}

Regarding this research subject, two interconnected features must be distinguished. The first relates to the economy being the dimension privileged by BIDs and their operations and, as the Figures 8 and 9 clearly illustrate, most of the selected literature reflected this orientation. This is not a literature bias, as BIDs were originally created to address the economic downfall of urban areas [84] and this is still the dimension most privileged in BID operations. It must also be stated that, assuming the role of the economic dimension does not mean that exceptions cannot be found. For instance, Prentice and Porter [85] analyzed how the Scottish national government faced BIDs as an instrument that was able to effectively address other issues (rather than the economic problems) and soon a strategic orientation towards a community-based intervention would be privileged [85]. 
However, economic enhancement is the distinguishing characteristic of BIDs, even when other designations are adopted, such as the community improvement districts in Georgia, U.S. [60].

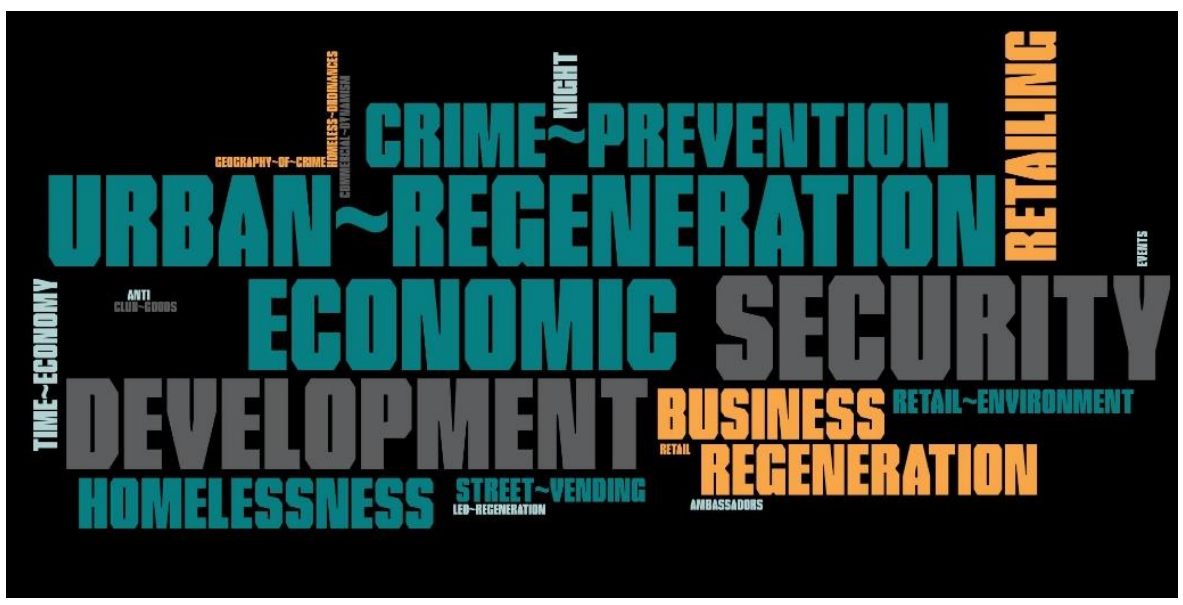

Figure 8. Word cloud, extracted from keywords that fit in dimension "Activities/Axis of intervention".



Figure 9. List of keywords from the research subject "Activities / Axis of intervention". Source: author (2021), after initial screening and selection of publications. Note: in this figure, only keywords with two or more listings were included.

Economic development, as a goal for BIDs is, thus, a solution to counteract the decline or underperformance of certain areas [86]. This privilege of the economic enhancement of the BID areas is due to the fact that businesses are the main financial contributors of the projects. Thus, their role in the definition of the business plan and the rightful expectations of having a return of the investment justifies this option. In this sense, the terms used in several publications (i.e., "urban revitalization" [55], "urban regeneration" [87] or just "regeneration" [5]) are too wide in their theoretical conception to be applied in interventions 
that usually aim to increase the economic viability of the area and the profitability of their businesses.

The second feature of this research subject, stressed in the selected literature, relates to the activities developed by BIDs regarding the completion of their goals (on a twofold). Firstly, some of the publications addressed the issue of the classification of activities. This matter is particularly consensual and assumes a somewhat descriptive stance. Based on this classification, the label 'clean, green and safe' [4] is traditionally used to define BID activities. Although this label still seems suitable to frame BIDs, some authors demonstrated that it may reduce the comprehensiveness and reach of the work developed by BIDs, mainly because it sets aside the component 'promotion, marketing and events', which holds a central role in BID operations. This issue is emphasized by different researchers, such as Ward and Cook [88], according to whom, BIDs tend to focus on: public space and maintenance; securing public spaces and businesses; marketing the BID area; and organizing events. In general, it seems that what is in question is not the activities, per se, but the way they are categorized. This is evident with Hoyt's [89] classification of activities. This author resorted to the 'clean, green and safe' categorization but replaced the 'green' for 'delightful' and included (in the latter category) marketing, promotional, and public relations activities. An interesting perspective was proposed by Gross [34], stressing the need to jointly consider whether a BID is implemented in a high-income area or in a low-income neighborhood, as well as the size of the BID itself; assuming these are key issues that will influence simultaneously: the available budget, the target consumers, and activities developed. Thus, this author [34] claimed it is expected that small BIDs focus on the physical maintenance of the BID area, medium-ranged BIDs devote to marketing and promotional campaigns, and large BIDs (beside these latter activities) also develop capital improvement activities. Secondly, some publications addressed security and related issues, which was not necessarily unexpected, as this is one of the activities labelled as essential in BIDs. Contrary to the analysis on the classification of activities, the publications focused on this issue adopted a more critical stance. It must also be stressed that this feature is strongly influenced by the national context in discussion. Most of the selected publications addressing security issues resorted to case studies in North America (especially in the U.S. [68,90-93] but also in Canada [77]), with less frequency in other countries: South Africa [94], Germany [35], and Sweden [95]. In the same rationale of security, the concerns regarding homelessness are to be highlighted. To this matter, while some authors argued that BIDs (due to their privileged advocacy and lobbying position within the urban governance network where they are located) may indeed contribute to solve homelessness problems $[4,96,97]$, other authors stressed that most actions towards homelessness are related to the beautification and commoditization of the area. Marquardt and Füller's [68] analysis of Los Angeles was illustrative of this latter perspective, in what the authors called the "selective masking of the homeless population". According to these authors, the approach in Los Angeles was more centered in dispersing the homeless population across a wider area of the city, making homelessness less visible for outsiders, which undoubtedly questions the ability of BIDs to solve certain kinds of problems and the spillover effects this may produce in other parts of the cities. So, from a critical perspective, that is somehow dominant in the selected literature that address this issue, the 'clean, green and safe' dimensions in BID activities have implied the creation of a 'better' economic environment or "a consumption environment free of refuse and risk for consumers to pass through unscathed", as mentioned by Lippert [77] (p. 169), at the expense of a certain level of urban segregation and social exclusion.

\subsection{BIDs: Various Types and Places of Intervention}

The most consensual issue of the literature on BIDs concerns the areas where they are implemented (Figure 10). The 'urban' seem to be central to this matter. This is not related to any discriminatory policy or attitude towards non-urban spaces, as the model is freely available to be developed ubiquitously, nor it is an issue that is directly approached 
by the authors in their publications. What seems to be key, in this understanding, is the existence of a minimum number of businesses, whose levy is able to form a budget expressive enough for the execution of the business plan considered necessary to improve the area. Moreover, as aforementioned, considering marketing and other related activities as essential in the work developed by BIDs, one is to expect a certain identity in the area and a number of businesses that enable the successful development of promotional activities. These types of actions are more likely to trigger consumer interest if the respective area offers a wide range of retail and services. These issues are not directly expressed by the selected literature, but we resort to two UK policy documents to attest to this (author note: the following two references are not a part of the selected publications, but we have chosen to add them to corroborate the issue, regarding the size of the BID area, that is missing in the analysed literature). A survey, conducted by the British BIDs organisation concluded that the typical number of businesses in each BID area ranged between 300 and 600 establishments [98]. In addition to the size of the commercial offer, UK policy documents stress the need for a certain homogeneity in the area: "There is no "right" size for a BID area. Each area is bespoke but it should make geographic sense to the issues being addressed by the proposed BID arrangements." [99] (p. 9); "Businesses should be contained within a clear geographic area and share common interests and objectives. The area must not be artificially extended or modelled e.g., to include hereditaments with high rateable values." [98] (p. 5). According to Ratcliffe and Flanagan [39], the challenge that arises from this dual necessity to implement BIDs in areas with a significant offering in retail and services and with a certain homogeneity, in terms of identity, is best addressed in urban areas.

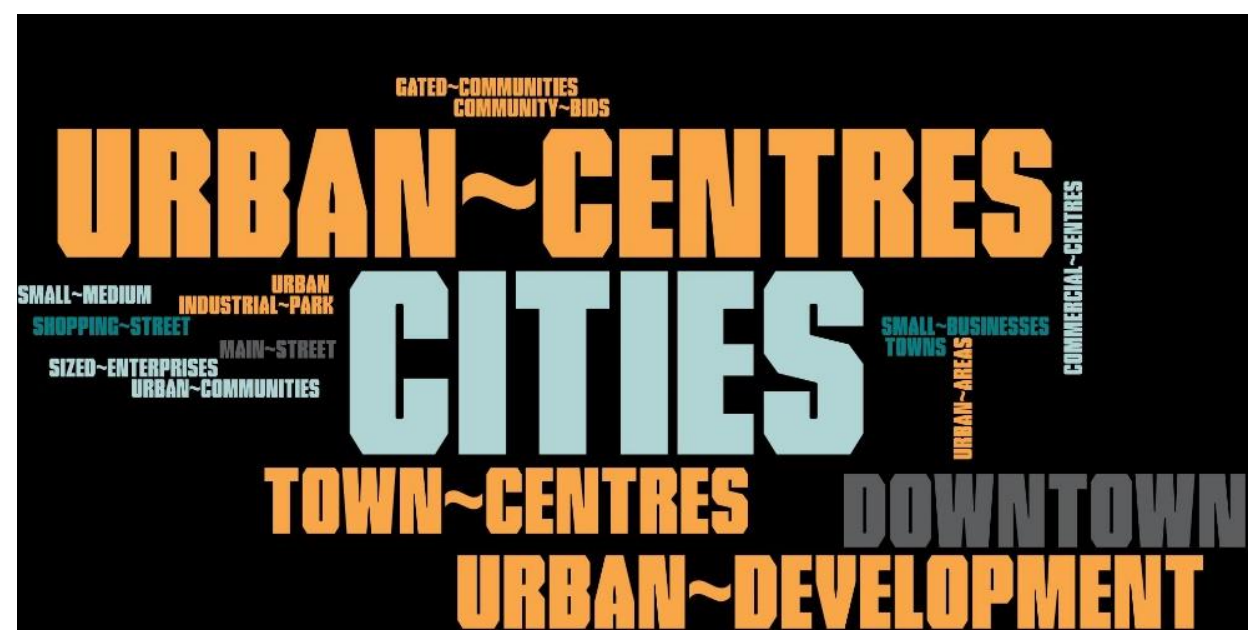

Figure 10. Word cloud, extracted from keywords, that fit in dimension "BIDs: various types and places of intervention".

Despite the literature identified urban central areas being the privileged locations for the implementation of BIDs, especially when combined with a substantial offer of retail and services, some authors stress that BIDs exist in other locations (Figure 11). Regarding this issue, Peel et al. [100] pointed to the existence of a significant variety of BIDs, such as leisure, industrial, and mixed-use BIDs. Drawing from a survey on UK BIDs, De Magalhães [4] adds to this point by classifying BIDs in four types: metropolitan core (involving central locations with a regional, national, or international influence); metropolitan periphery (areas within metropolises but outside of central business districts); town centres (central areas of non-metropolitan conurbations, with a mix of local and regional catchment areas); and industrial areas and business parks on the edge or outside of urban areas. Indeed, if most BIDs are clearly urban-centred and focused on the commercial revitalization of different types of central areas, as aforementioned, the literature shows that the BID model is not constrained within these boundaries. The work of Monterrey-Meana [101] points 
in this direction. Assuming the partnership between industrial business owners and the execution of common services to be a best practice, in terms of the management of industrial areas, this author stressed the viability of the BID model for such business environments. In this sense, the type of BID (commercial, leisure, industrial, or other) is strongly linked with the place where it is developed. The same occurs with other sectors, such as housing. Brenner [102] analysed the German context (in particular, the city of Hamburg) where the BID model has been applied to housing in the designated housing improvement districts (HID). The author stressed that even the legislation that regulates both models is quite similar. If BIDs aim to 'to make central commercial and service areas more attractive for consumers, visitors and inhabitants' [102] (p. 221), the HID goal is to improve the quality of housing and life in that particular area, to stabilize and to make it more attractive [102] (p. 223). This approach is similar to what was developed in Malmo, Sweden, where Kronkvist and Ivert [95] analysed a BID that was implemented in an inner-city residential neighbourhood to improve the residents living conditions, in particular to tackle rising crime rates. Through an integrated approach, combining physical improvements, enhanced public area maintenance, and additional security, those authors concluded that no definitive and general conclusion can be obtained regarding the effectiveness of Malmo BIDs in tackling crime. Still, they stress that some positive cumulative impacts may be felt in a period of time that surpasses their particular research timeline. This type of intervention from a BID is a good example of a practical application of the broken window theory, as already applied in other BIDs (see, for instance, D'Souza [90]).

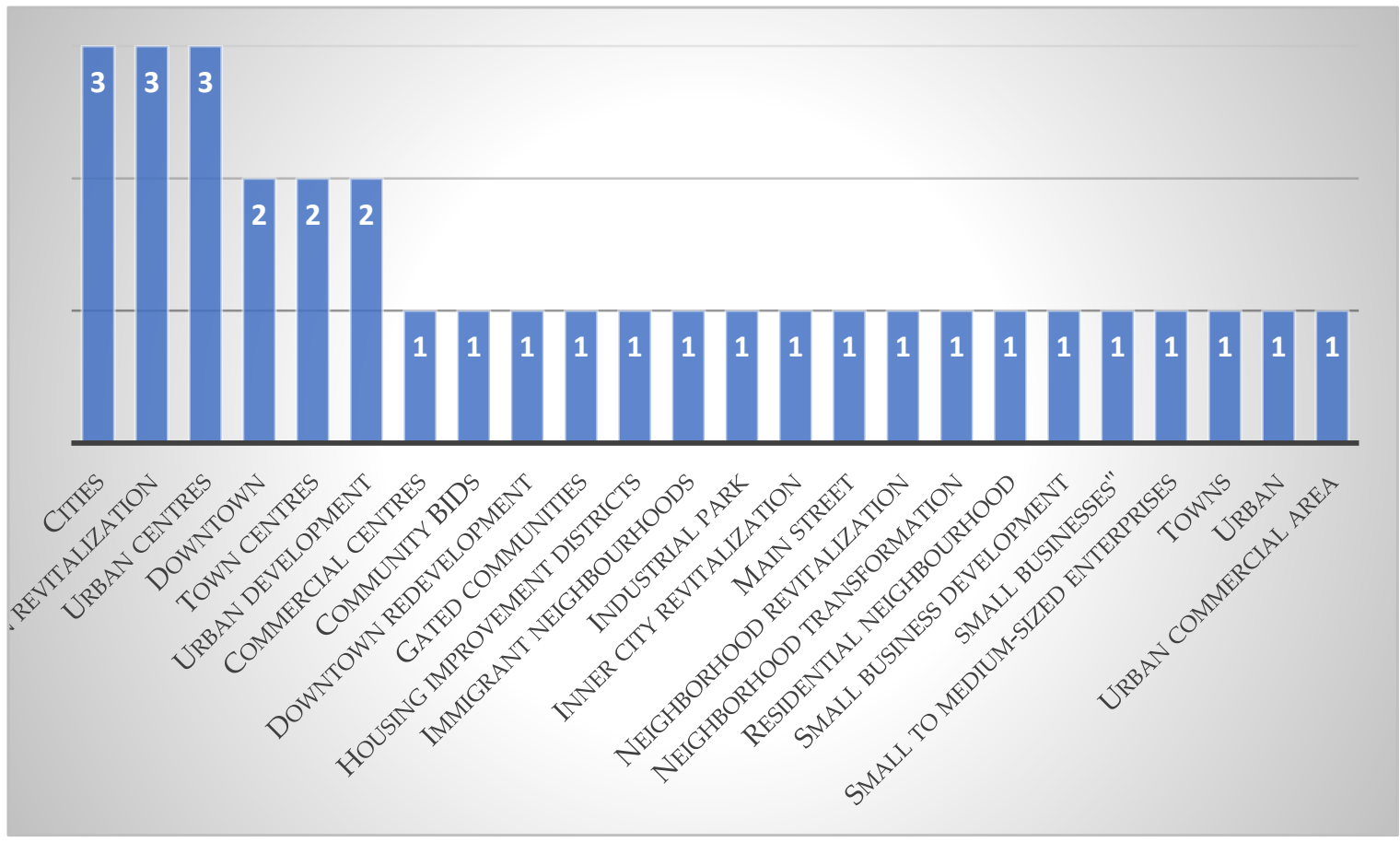

Figure 11. List of keywords from the research subject "BIDs: various types and places of intervention". Source: author (2021), after initial screening and selection of publications.

\section{Discussion and Conclusions}

The evolution of urban spaces frequently provokes the decline of some areas and, consequently, the enactment of urban policies, programs, and projects that sought to solve it. BIDs fit within this line of evolution, as a measure to improve the viability of certain areas. Analyzing BIDs is a complex task because of its multifaceted nature. From the initial standpoint of BIDs, as essentially a new approach of retail-led urban regeneration, this study has shown that this model is a multilayer approach for urban revitalization. The 
main objective for the implementation of BIDs is clearly the economic enhancement of the businesses in delimited areas. An initial overview points to the success of this model in achieving such goal, which is essentially validated by the wide range of countries that have adopted this model as a good practice in urban planning. What the selected literature for this study has shown is this is a too narrow of a vision for the subject being analyzed.

The choice for a systematic review and PRISMA protocol for its development was due to the author prior knowledge of the limitations of some of the existing literature regarding BIDs. These limitations are essentially related to the comprehensiveness of their scope (a gap that this study confirmed) and, to some extent, contributed to address it. The 141 publications retrieved from the SCOPUS database is a small number, especially if compared to the current importance of BIDs as an urban planning tool for central area revitalization. In our opinion, three reasons help explain this. Firstly, BID implementation in different countries is closely linked with the action of local authorities that may favor other means of communication, rather than the traditional scientific outputs. Secondly, our search was restricted to the term "Business Improvement Districts", which may hinder specific designations adopted in other countries, such as 'special improvement districts', 'public improvement districts', or 'downtown improvement districts', as Ward [41] referenced. Despite our term used for search, the 141-sample used in this study provided evidence and a solid basis to unfold and discuss the four main research subjects. Thirdly, although it is an urban regeneration model that dates some decades now, it is mainly in the new millennium that the worldwide dissemination of the model occurred. In this period, BIDs (as a concept and an urban planning practice) received particular attention from the scientific community, especially associated with discussions on policy transfer.

The link between the four main research subjects was found to be significant. It must also be noted that these subjects are not a mere reflex of the topics privileged by the authors in their research. Instead, they reflect the nature of BIDs, as well as their design and operationalization. Still, they do not possess the same degree of importance, mainly because the main two research subjects, 'Urban Governance' and 'Urban policies: mobility and transfer', refer to fundamental concerns and challenges of the implementation and execution of BIDs in certain areas and the impacts therein provoked. The remaining two research subjects, 'BIDs: various types and places of intervention' and 'Activities / Axis of intervention', assume a contextual stance, often arising in the publications, not as the main object of analysis but as the contextualization of the characteristics of the respective area and BID projects.

Regarding the research subject 'BIDs: various types and places of intervention', our analysis confirmed that urban centers are the preferred locations for the development of BIDs. This characteristic is strongly linked with the fact that most BIDs are oriented for business revitalization. Thus, areas with a robust concentration of retail and services foster the potential capacity of attracting consumers to the area and ensure an attractive budget for the execution of the business plans. Consequently, high streets and other relevant commercial axes, where a significant number of businesses can be found, fit the requirements for the execution of BIDs.

This feature ends up influencing the elements that characterize the research subject 'Activities/Axis of intervention'. It then comes as no surprise that most activities relate to the beautification of the area, creating a commercial environment attractive for consumers. This is achieved through a wide set of activities, such as additional cleaning, improvement of the urban furniture, creation of an area of common identity, and marketing, as well as services that aim to assure the area's security (including the prevention and exclusion of homelessness).

The other two research subjects have greater prominence in the analyzed publications. In the research subject 'Urban Governance', BIDs are classified as a neoliberal mechanism and a new form of cities' governance, often resorting to a critical stance. Frequently, what is in question is not the added-value of an inclusive urban revitalization model that has some characteristics of a bottom-up approach, in which public and private agents form a 
partnership and are equally involved in a process of co-creation [103]. This positive opinion is in line with several researchers. On this matter, Hemphill et al. [87] (p. 680) recognize that BIDs has a "significant leverage potential whilst acting as a key conduit for coordinating wider area-based regeneration". Stokes [84] (p. 279) corroborates this idea by stressing the notion of BIDs "as effective agents of small business organization, promotion, and place management". On this research subject, one main concern identified in the literature relays on the restructuring of the urban governance structure of the city or region where the BID is located. BIDs do not necessarily imply that these new organizations will replace public authorities as providers of certain activities and services. Nevertheless, several authors demonstrate concerns over the privatization of urban areas, as these organizations will be conceded power to act in areas public in their 'nature', which ultimately is an act of political significance, as argued by Mendel [69]. Within this standpoint, the delegation of powers to private agents is a neoliberal approach that disclaims public authorities from the fate of those given areas. Moreover, because not everyone in the area may be eligible to vote for the approval of the respective BID, some groups of the population may be situated in a void, in what concerns their representativeness. If, under this understanding, BIDs are to be seen as private governments, as suggested by Meltzer [104], new challenges for urban governance are raised. As Briffault [65] advocates, the integration of BIDs into the urban governance structure represents a fusion with the traditional governing institutions. On the one hand, the constitution and dissemination of BIDs throughout a given city will represent the pinnacle of a neoliberal stance in cities' governance. On the other hand, the implementation of a BID requires the existence of a certain social and economic capital. Because the activities carried out by BIDs depend on the levy collected, this means that BIDs in areas with more rateable value can develop activities of greater impact and, therefore, enhance the performance of the respective area. Eventually, this may provoke a cleavage with areas that have no BID or that have BIDs of smaller dimensions. Ultimately, this may lead to an increase of the spatial segregation of the city.

Lastly, under the research subject 'urban policies: mobility and transfer', policy transfer is seen as constructive, as it represents the exportation of a policy from places where it succeeds to other places that aim to adopt new ideas for urban revitalization. Contrary to what one would expect, as some authors mention [36,70], BID models that reproduce themselves through the process of globalization do not necessarily result in the homogenization of places, as local specificities are key in the development of BIDs. The importance of the characteristics of each area is to be seen, not only in the international transfer. To this matter, Lee [105] argues that BIDs may not work in all areas. For instance, in some areas, businesses may not be in decline and, consequently, their owners may not think it is necessary to run a BID project in the area. Another perspective (at the national scale) would be that some countries may be more likely to adopt BIDs. On this issue, Peel and Lloyd [106], using the UK example, clarified that it was the previous experience with town centre management schemes (that demonstrated the relevance of public-private partnerships for town centre revitalization) that paved the way for the success of BIDs in the UK. The literature also draws attention to the means through which the BID model is transferred and in what is designated as transfer agents [76]. On the one hand, it is highlighted that the role of academic means of communication, such as some journal's special issues or conferences, on the subject are significant $[58,75]$. This latter type of events was found to be particularly relevant in allowing different stakeholders, such as academics and practitioners, to get involved in the knowledge sharing process. On the other hand, transfer agents may be respected individuals that represent successful projects elsewhere. Urban planners also play a key role. In their benchmarking for solutions for their cities, these latter agents adopt the worldwide disseminated model of BIDs and adapt it to the respective area's characteristics. By proceeding in such a manner, the process through which BIDs rationale of intervention becomes a glocal policy is concluded.

The performed study of BIDs sheds some light on the need for future research on specific issues. The first concerns the aforementioned question of urban governance. The 
analyzed literature assumed the importance of BIDs in the rearrangement of the urban governance networks in the areas where they are implemented. However, less is mentioned regarding the spillover impacts that BIDs provoke in the surrounding areas that do not run a BID project, as well as the implications, in terms of the restructuring of the traditional urban retail systems at different scales. In addition, how justifiable is the active role of local public authorities in the development of a BID in a certain area, if negative spillover effects are to be found in other parts of the city? The second issue regards the social dimension. As it became clear, BIDs operate in the economic sphere-normal if one considers that projects are mostly funded by private businesses. However, BIDs are executed in public areas, which implies that different citizens will be directly or indirectly impacted by BID operations. Thus, in addition to concerns already raised by the literature regarding the accountability of those operations, research is needed to understand how BIDs act, interact, and impact with the social sustainability of the areas where projects are implemented. This issue is particularly important, if one considers the growing and recent valorization at the local scale, as attested by the 15-min city and other local communities' initiatives.

As a final remark, in terms of limitations, we would like to acknowledge that the choices we made regarding the identification of studies may have excluded other studies, such as books, articles available in other databases (such as Scielo), and texts written in other languages; these choices are mostly justified by our option of favoring the possibility of this study being replicated exactly in the future, following the same guidelines used in this research.

Funding: This research was funded by Fundação para a Ciência e a Tecnologia Project 'PHOENIXRetail-Led Urban Regeneration and the New Forms of Governance'-PTDC/GES-URB/31878/2017).

Acknowledgments: We would like to acknowledge the support from the journal editors, as well as the editorial board.

Conflicts of Interest: The authors declare no conflict of interest.

\section{References}

1. Guimarães, P.; Cachinho, H. Business improvement districts: Concepto y experiencias. In Ciudad, Comercio y Consumo: Temas y Problemas Desde la Geografía; Silveira, M., Bertoncello, R., Nucci, J., Eds.; Editorial Café de las Ciudades: Buenos Aires, Argentina, 2020; pp. 665-679.

2. Charenko, M. A Historical Assessment of the World's First Business Improvement Area (BIA): The Case of Toronto's Bloor West Village. Can. J. Urban Res. 2015, 24, 1-19.

3. Morçöl, G.; Vasavada, T.; Kim, S. Business Improvement Districts in Urban Governance: A Longitudinal Case Study. Adm. Soc. 2014, 46, 796-824. [CrossRef]

4. De Magalhães, C. Business Improvement Districts and the recession: Implications for public realm governance and management in England. Prog. Plan. 2012, 77, 143-177. [CrossRef]

5. McCarthy, J.; Doyle, M. Business improvement districts and conservation-led regeneration. Urban Res. Pract. 2011, 4, 175-192. [CrossRef]

6. Kim, H.; Jang, Y. Lessons from good and bad practices in retail-led urban regeneration projects in the Republic of Korea. Cities 2017, 61, 36-47. [CrossRef]

7. Hall, T. Urban Geography, 3rd ed.; Routledge: Oxon, UK, 2006.

8. Roberts, P. The Evolution, Definition and Purpose of Urban Regeneration. In Urban Regeneration-A handbook; Roberts, P., Sykes, H., Eds.; SAGE Publications: London, UK, 2000; pp. 3-8.

9. Tallon, A. Urban Regeneration in the UK; Routledge: New York, NY, USA, 2010.

10. Alves, S. Conflitos institucionais no âmbito da Capital Europeia da Cultura Porto 2001. Finisterra 2017, 104, 39-56. [CrossRef]

11. Balsas, C. City centre regeneration in the context of the 2001 European capital of culture in Porto, Portugal. Local Econ. 2004, 19, 396-410. [CrossRef]

12. Heidenreich, M.; Plaza, B. Renewal through Culture? The Role of Museums in the Renewal of Industrial Regions in Europe. Eur. Plan. Stud. 2015, 23, 8. [CrossRef]

13. Plaza, B.; Tironi, M.; Haarich, S. Bilbao's Art Scene and the "Guggenheim effect" Revisited. Eur. Plan. Stud. 2009, 17, 1711-1729. [CrossRef]

14. Guimarães, P. An evaluation of urban regeneration: The effectiveness of a retail-led project in Lisbon. Urban Res. Pract. 2017, 10, 350-366. [CrossRef] 
15. Grimsey, B.; Hopkinson, M.; Hood, N.; Pascoe, E.; Shellard, C.; Sadek, J.; Hill, E.; Cassidy, K.; Dehullu, V.; Baker, M. The Grimsey Review 2. Vanishinghighstreet, 2018. Available online: http://www.vanishinghighstreet.com/wp-content/uploads/2018/07/ GrimseyReview2.pdf (accessed on 1 July 2021).

16. The Scottish Government. National Review of Town Centres External Advisory Group Report: Community and Enterprise in Scotland's Town Centres; The Scottish Government: Edinburgh, UK, 2013.

17. Jacques, T. The state, small shops and hypermarkets: A public policy for retail, France, 1945-1973. Bus. Hist. 2017, 60, 1026-1048. [CrossRef]

18. Guimarães, P. 2016 Revisiting retail planning policies in countries of restraint of Western Europe. Int. J. Urban Sci. 2016, 20, 361-380. [CrossRef]

19. Guy, C. Planning for Retail Development, a Critical View of the British Experience; Routledge: Oxon, UK, 2007.

20. Sparks, L. Towns, High Streets and Resilience in Scotland: A Question for Policy? Sustainability 2021, 13, 5631. [CrossRef]

21. Davies, R. (Ed.) Retail Planning Policies in Western Europe; Routledge: London, UK, 1995.

22. Reynolds, J.; Cuthbertson, C. (Eds.) Retail Strategy, the View from the Bridge; Elsevier: Oxford, UK, 2004.

23. Lowe, M. Revitalizing inner city retail? The impact of the West Quay development on Southampton. Int. J. Retail Distrib. Manag. 2005, 33, 658-668. [CrossRef]

24. Lowe, M. Rethinking Southampton and town centre futures. Int. J. Retail Distrib. Manag. 2007, 35, 639-646. [CrossRef]

25. Jones, P.; Hillier, D.; Comfort, D. Business improvement districts in town and city centres in the UK. Manag. Res. News 2003, 26, 50-59. [CrossRef]

26. Guimarães, P. Town Centre Management: Outlook from Portugal. Plan. Pract. Res. 2018, 33, 18-33. [CrossRef]

27. Hogg, S.; Medway, D.; Warnaby, G. Town centre management schemes in the UK: Marketing and performance indicators. Int. J. Nonprofit Volunt. Sect. Mark. 2004, 9, 309-319. [CrossRef]

28. Sommella, R.; Viganoni, L.; D'AAlessandro, L.; Guadagno, E. Critical reflections on regeneration, retail and consumption: Naples as a fragmented city. In Comércio, Consumo \& Governança Urbana; Cachinho, H., Barata-Salgueiro, T., Guimarães, P., Eds.; CEG: Lisbon, Portugal, 2020; pp. 380-394.

29. Espinosa, A.; Hernandez, T. A comparison of public and private partnership models for urban commercial revitalization in Canada and Spain. Can. Geogr. 2016, 60, 107-122. [CrossRef]

30. Warnaby, G.; Bennison, D.; Davies, B. Retailing and the Marketing of Urban Places: A UK Perspective. Int. Rev. Retail Distrib. Consum. Res. 2005, 15, 191-215. [CrossRef]

31. Medway, D.; Warnaby, G.; Bennison, D.; Alexander, A. Reasons for retailers' involvement in town centre management. Int. J. Retail Distrib. Manag. 2000, 28, 368-378. [CrossRef]

32. Peel, D.; Lloyd, M. A case for business improvement districts in Scotland: Policy transfer in practice? Plan. Pract. Res. 2005, 20, 89-95. [CrossRef]

33. Elmedni, B.; Christian, N.; Stone, C. Business improvement districts (BIDs): An economic development policy or a tool for gentrification. Cogent Bus. Manag. 2018, 5, 1502241. [CrossRef]

34. Gross, J. Business Improvement Districts in New York City's Low-Income and High-Income Neighborhoods. Econ. Dev. Q. 2005, 19, 174-189. [CrossRef]

35. Eick, V. The co-production of purified space: Hybrid policing in German Business Improvement. Dist. Eur. Urban Reg. Stud. 2012, 19, 121-136. [CrossRef]

36. Michel, B. A Global Solution to Local Urban Crises? Comparing Discourses on Business Improvement Districts in Cape Town and Hamburg. Urban Geogr. 2013, 34, 1011-1030. [CrossRef]

37. Didier, S.; Morange, M.; Peyroux, E. The Adaptative Nature of Neoliberalism at the Local Scale: Fifteen Years of City Improvement Districts in Cape Town and Johannesburg. Antipode 2013, 45, 121-139. [CrossRef]

38. Grail, J.; Mitton, C.; Ntounis, N.; Parker, C.; Quin, S.; Steadman, C.; Warnaby, G.; Cotterill, E.; Smith, D. Business improvement districts in the UK: A review and synthesis. J. Place Manag. Dev. 2019, 13, 73-88. [CrossRef]

39. Ratcliffe, J.; Flanagan, S. Enhancing the vitality and viability of town and city centres: The concept of the business improvement district in the context of tourism enterprise. Prop. Manag. 2004, 22, 377-395. [CrossRef]

40. Mullin, J.; Kotval, Z.; Measuring the Effectiveness of Downtown Revitalization Strategies. NYCOM Bulletin. 2003, p. 23. Available online: https: / / scholarworks.umass.edu/larp_faculty_pubs/23 (accessed on 15 July 2021).

41. Ward, K. Business Improvement Districts: Policy Origins, Mobile Policies and Urban Liveability. Geogr. Compass 2007, 1, 657-672. [CrossRef]

42. Villarejo-Galende, H.; Pardo, M.; García, C. Smart cities: Can business improvement districts reduce the environmental footprint of urban areas? In Environmental Fiscal Challenges for Cities and Transport; Ezcurra, M., Milne, J., Ashiabor, H., Anderson, M., Eds.; Edward Elgar Publishing: Cheltenham, UK, 2019; pp. 46-59.

43. Hoyt, L.; Gopal-Agge, D. The Business Improvement District Model: ABalanced Review of Contemporary Debates. Geogr. Compass 2007, 1, 946-958. [CrossRef]

44. Morçöl g Hoyt, L.; Meek, J.; Zimmermann, U. Business Improvement Districts-Research, Theories and Controversies; CRC Press: Oxon, UK, 2008.

45. Prifti, R.; Jaupi, F. Entrepreneurial Urban Regeneration-Business Improvement Districts as a Form of Organizational Innovation; Routledge: New York, NY, USA, 2020. 
46. Sarkis-Onofre, R.; Catalá-López, F.; Aromataris, E.; Lockwood, C. How to properly use the PRISMA Statement. Syst. Rev. 2021, 10, 117. [CrossRef]

47. Moher, D.; Liberati, A.; Tetzlaff, J.; Altman, D.G.; The PRISMA Group. Preferred Reporting Items for Systematic Reviews and Meta-Analyses: The PRISMA Statement. PLoS Med. 2009, 6, e1000097. [CrossRef]

48. Jordan, K.; Lewis, T.; Roberts, B. Quality in crisis: A systematic review of the quality of health systems in humanitarian settings. Confl. Health 2021, 15, 7. [CrossRef]

49. Riche, C.; Aubin, D.; Moyson, S. Too much of a good thing? A systematic review about the conditions of learning in governance networks. Eur. Policy Anal. 2021, 7, 147-164. [CrossRef]

50. Page, M.J.; McKenzie, J.E.; Bossuyt, P.M.; Boutron, I.; Hoffmann, T.C.; Mulrow, C.D.; Mulrow, C.D.; Shamseer, L.; Tetzlaff, J.M.; Akl, E.A.; et al. The PRISMA 2020 statement: An updated guideline for reporting systematic reviews. BMJ 2021, $372,71$. [CrossRef]

51. Han, S.; Morçöl, G.; Hummer, D.; Peterson, S. The effects of business improvement districts in reducing nuisance crimes: Evidence from Philadelphia. J. Urban Aff. 2017, 39, 658-674. [CrossRef]

52. Ziebarth, D. Business Improvement Districts and Contemporary Local Governance. State Local Gov. Rev. 2020, 52, 128-137. [CrossRef]

53. Brettmo, A.; Browne, M. Business Improvement Districts as important influencers for changing to sustainable urban freight. Cities 2020, 97, 102558. [CrossRef]

54. Wee, L. Language policy, homelessness andneoliberal urbanization: The case ofSan Francisco's Union Square. J. Socioling. 2016, 20, 263-286. [CrossRef]

55. Kizildere, D.; Chiodelli, F. Discrete emergence of neoliberal policies on public space: An informal Business Improvement District in Istanbul, Turkey. Urban Geogr. 2018, 39, 783-802. [CrossRef]

56. Richner, M.; Olesen, K. Towards business improvement districts in Denmark: Translating a neoliberal urban intervention model into the Nordic context. Eur. Urban Reg. Stud. 2019, 26, 158-170. [CrossRef]

57. Shaw, R. 'Alive after five': Constructing the neoliberal night in Newcastle upon Tyne. Urban Stud. 2015, 52, 456-470. [CrossRef]

58. Michel, B.; Stein, C. Reclaiming the European City and Lobbying for Privilege: Business Improvement Districts in Germany. Urban Aff. Rev. 2015, 51, 74-98. [CrossRef]

59. Valli, C.; Hammami, F. Introducing Business Improvement Districts (BIDs) in Sweden: A social justice appraisal. Eur. Urban Reg. Stud. 2021, 28, 155-172. [CrossRef]

60. Ewoh, A.; Rome, K. Community improvement districts in Georgia: Administrators' views on their effectiveness, performance, and accountability. Public Perform. Manag. Rev. 2012, 36, 203-215. [CrossRef]

61. Browne, M.; Allen, J.; Alexander, P. Business improvement districts in urban freight sustainability initiatives: A case study approach. Transp. Res. Procedia 2016, 12, 450-460. [CrossRef]

62. Ha, S.; Grunwell, S. Estimating the economic benefits a business improvement district would provide for a downtown central business district. J. Econ. Econ. Educ. Res. 2014, 15, 89-102.

63. Gross, J. Business improvement districts in New York: The private sector in public service or the public sector privatized? Urban Res. Pract. 2013, 6, 346-364. [CrossRef]

64. Morçöl, G.; Karagoz, T. Accountability of Business Improvement District in Urban Governance Networks: An Investigation of State Enabling Laws. Urban Aff. Rev. 2020, 56, 888-918. [CrossRef]

65. Briffault, R. A Government for Our Time? Business Improvement Districts and Urban Governance. Columbia Law Rev. 1999, 99, 365-477. [CrossRef]

66. Justice, J.; Goldsmith, R. Private Governments or Public Policy Tools? The Law and Public Policy of New Jersey's Special Improvement Districts. Int. J. Public Adm. 2006, 29, 107-136. [CrossRef]

67. Ward, K. Entrepreneurial Urbanism and Business Improvement Districts in the State of Wisconsin: A Cosmopolitan Critique. Ann. Assoc. Am. Geogr. 2010, 100, 1177-1196. [CrossRef]

68. Marquardt, N.; Füller, H. Spillover of the private city: BIDs as a pivot of social control in downtown Los Angeles. Eur. Urban Reg. Stud. 2012, 19, 153-166. [CrossRef]

69. Mendel, S. Are private government, the nonprofit sector, and civil society the same thing? Nonprofit Volunt. Sect. Q. 2010, 39, 717-733. [CrossRef]

70. Brooks, L.; Strange, W. The micro-empirics of collective action: The case of business improvement districts. J. Public Econ. 2011, 95, 1358-1372. [CrossRef]

71. Becker, C. Democratic Accountability and Business Improvement Districts. Public Perform. Manag. Rev. 2012, 36, 187-202. [CrossRef]

72. Peyroux, E.; Pütz, R.; Glasze, G. Business Improvement Districts (BIDs): The internationalization and contextualization of a 'travelling concept'. Eur. Urban Reg. Stud. 2012, 19, 181-194. [CrossRef]

73. Stein, C.; Michel, B.; Gasze, G.; Putz, R. Learning from failed policy mobilities: Contradictions, resistances and unintended outcomes in the transfer of "Business Improvement Districts" to Germany. Eur. Urban Reg. Stud. 2017, 24, 35-49. [CrossRef]

74. Tait, M.; Jensen, O. Travelling Ideas, Power and Place: The Cases of Urban Villages and Business Improvement Districts. Int. Plan. Stud. 2007, 12, 107-128. [CrossRef] 
75. Cook, I.; Ward, K. Conferences, informational infrastructures and mobile policies: The process of getting Sweden 'BID ready'. Eur. Urban Reg. Stud. 2012, 19, 137-152. [CrossRef]

76. McCann, E.; Ward, K. A multi-disciplinary approach to policy transfer research: Geographies, assemblages, mobilities and mutations. Policy Stud. 2013, 34, 2-18. [CrossRef]

77. Lippert, R. ‘Clean and safe' passage: Business Improvement Districts, urban security modes, and knowledge brokers. Eur. Urban Reg. Stud. 2012, 19, 167-180. [CrossRef]

78. Peyroux, E. Legitimating Business Improvement Districts in Johannesburg: A discursive perspective on urban regeneration and policy transfer. Eur. Urban Reg. Stud. 2012, 19, 111-120. [CrossRef]

79. Meek, J.; Hubler, P. Business Improvement Districts in Southern California: Implications for Local Governance. Int. J. Public Adm. 2006, 29, 31-52. [CrossRef]

80. Wolf, J. Urban Governance and Business Improvement Districts: The Washington, DC BIDs. Int. J. Public Adm. 2006, 29, 53-75. [CrossRef]

81. Morçöl, G.; Patrick, P. Business Improvement Districts in Pennsylvania: Implications for Democratic Metropolitan Governance. Int. J. Public Adm. 2006, 29, 137-171. [CrossRef]

82. Stokes, R. Business Improvement Districts and Inner City Revitalization: The Case of Philadelphia's Frankford Special Services District. Int. J. Public Adm. 2006, 29, 173-186. [CrossRef]

83. Morçöl, G.; Zimmermann, U. Community Improvement Districts in Metropolitan Atlanta. Int. J. Public Adm. 2006, 29, 77-105. [CrossRef]

84. Mitchell, J. Business Improvement Districts and the "New" Revitalization of Downtown. Econ. Dev. Q. 2001, 15, 115-123. [CrossRef]

85. Prentice, P.; Porter, I. Business Improvement Districts and Town Centre Management: What has been their effectiveness and what are the future directions for these strategies? J. Urban Regen. Renew. 2015, 8, 228-232.

86. Stokes, R. Business Improvement Districts and Small Business Advocacy: The Case of San Diego's Citywide BID Program. Econ. Dev. Q. 2007, 21, 278-291. [CrossRef]

87. Hemphill, L.; Berry, J.; McGreal, S. A financial appraisal of business improvement districts in the UK. Environ. Plan. C Gov. Policy 2014, 32, 680-696. [CrossRef]

88. Ward, K.; Cook, I. Business Improvement Districts in the UK: Territorialising a 'global' model? In Territorial Policy and Governance: Alternative Paths; Deas, I., Hincks, S., Eds.; Taylor \& Francis: Abingdon, UK, 2017; pp. 127-146.

89. Hoyt, L. Importing Ideas: The Transnational Transfer of Urban Revitalization Policy. Int. J. Public Adm. 2006, $29,221-243$. [CrossRef]

90. D'Souza, A. An Examination of Order Maintenance Policing by Business Improvement Districts. J. Contemp. Crim. Justice 2020, 36, 70-85. [CrossRef]

91. Vindevogel, F. Private security and urban crime mitigation: A bid for BIDs. Crim. Justice 2005, 5, 233-255. [CrossRef]

92. Clutter, J.; Henderson, S.; Haberman, C. The Impact of Business Improvement District Proximity on Street Block Robbery Counts. Crime Deliquency 2019, 65, 1051-1075. [CrossRef]

93. Hoyt, L. Do Business Improvement District Organizations Make a Difference? Crime In and Around Commercial Areas in Philadelphia. J. Plan. Educ. Res. 2005, 25, 185-199. [CrossRef]

94. Bénit-Gbaffou, C. Unbundled security services and urban fragmentation in post-apartheid Johannesburg. Geoforum 2008, 39, 1933-1950. [CrossRef]

95. Kronkvist, K.; Ivert, A. A winning BID? The effects of a BID-inspired property owner collaboration on neighbourhood crime rates in Malmö, Sweden. Crime Prev. Community Saf. 2020, 22, 134-152. [CrossRef]

96. Lee, W. Downtown management and homelessness: The versatile roles of business improvement districts. J. Place Manag. Dev. 2018, 11, 411-427. [CrossRef]

97. Lee, W.; Ferguson, K. The role of local businesses in addressing multidimensional needs of homeless populations. J. Hum. Behav. Soc. Environ. 2019, 29, 389-402. [CrossRef]

98. British BIDS. Business Plan Criteria for Business Improvement Districts. 2020. Available online: https://britishbids.info/ publications / business-plan-criteria-for-bids (accessed on 24 June 2021).

99. Department for Communities and Local Government (DCLG). Business Improvement Districts Guidance and Best Practice. 2015. Available online: https:/ / cdn.britishbids.info/publications /BIDs_Guidance_and_Best_Practice.pdf?mtime=20180227104017 (accessed on 24 June 2021).

100. Peel, D.; Lloyd, G.; Lord, A. Business Improvement Districts and the Discourse of Contractualism. Eur. Plan. Stud. 2009, 17, 401-422. [CrossRef]

101. Monterrey-Meana, M. Definition of a public-private management model for industrial estates in Spain based in the business improvement districts system. Dyna 2013, 88, 41-48. [CrossRef]

102. Brenner, J. Private initiatives in German urban development policy. Urban Res. Pract. 2010, 3, 219-228. [CrossRef]

103. Brunetta, G.; Caldarice, O. Self-organization and retail-led regeneration: A new territorial governance within the Italian context. Local Econ. 2014, 29, 334-344. [CrossRef]

104. Meltzer, R. Understanding Business Improvement District formation: An analysis of neighborhoods and boundaries. J. Urban Econ. 2012, 71, 66-78. [CrossRef] 
105. Lee, W. Struggles to form business improvement districts (BIDs) in Los Angeles. Urban Stud. 2016, 53, 3423-3438. [CrossRef]

106. Peel, D.; Lloyd, G. Re-generating Learning in the Public Realm Evidence-based Policy Making and Business Improvement Districts in the UK. Public Policy Adm. 2008, 23, 189-205. 